\title{
IMpower, CASPIAN, and more: exploring the optimal first-line immunotherapy for extensive-stage small cell lung cancer
}

\author{
Chengliang Huang ${ }^{1,2}$, Gregory N. Gan ${ }^{3,4}$ and Jun Zhang ${ }^{2,4^{*}}$ (D)
}

\begin{abstract}
The life expectancy of extensive-stage small cell lung (ES-SCLC) cancer patients has not improved in the last 2-3 decades until two recent trials (CASPIAN and IMpower133) showing the addition of anti-programmed death ligand (PD-L1) therapy to chemotherapy has survival benefit over chemotherapy alone. However, such benefit is relatively small and was not even observed in some other trials using immunotherapy, raising the question of optimal chemoimmunotherapy combination in the 1st-line setting for ES-SCLC. Here, we discussed several thoughtprovoking questions with the focus on IMpower133 and CASPIAN trials.
\end{abstract}

Keywords: Extensive-stage small cell lung cancer, Immunotherapy, PD-1, PD-L1, Radiation therapy, CTLA-4, CD80, CD28, TIGIT, CD155 (PVR)

\section{To the Editor,}

The life expectancy of extensive-stage small cell lung cancer (ES-SCLC) patients has not improved in the last 2-3 decades until two recent trials (CASPIAN [1] and IMpower133 [2]) showing the addition of anti-programmed death ligand (PD-L1) therapy to chemotherapy has survival benefit over chemotherapy alone. However, such benefit is relatively small and was not even observed in some other immunotherapy trials, e.g., CA184-156 study using anti-cytotoxic T cell lymphocyte antigen-4 (CTLA-4) agent ipilimumab [3], raising the question of optimal chemoimmunotherapy combination in the 1st-line setting for ES-SCLC.

Both IMpower133 and CASPIAN were multi-center, phase III randomized studies that reached their primary endpoint of overall survival (OS) benefit. In both studies,

\footnotetext{
* Correspondence: jzhang3@kumc.edu

Division of Medical Oncology, Department of Internal Medicine, University of Kansas Cancer Center, University of Kansas Medical Center, 3005 Wahl Hall East, 3901 Rainbow Blvd, Kansas City, KS 66160, USA

${ }^{4}$ Department of Cancer Biology, University of Kansas Cancer Center, University of Kansas Medical Center, 3901 Rainbow Blvd, Kansas City, KS 66160, USA

Full list of author information is available at the end of the article
}

the median OS (mOS) was significantly longer in the immunotherapy plus platinum-etoposide group compared to the platinum-etoposide alone group (CASPIAN: 13 [95\% CI 11.5-14.8] vs. 10.3 [95\% CI 9.3-11.2] months; IMpower133: 12.3 [95\% CI 10.8-15.9] vs. 10.3 [95\% CI 9.3-11.3] months) (Table 1). Similarly, the progressionfree survival (PFS) benefit was observed. The IMpower133 demonstrated that the median PFS (mPFS) was longer in the combined therapy arm (5.2 months [95\% CI 4.4-5.6]) compared to the chemotherapy alone arm (4.3 months [95\% CI 4.2-4.5]). In the CASPIAN trial, although the mPFS was insignificant, the 1-year progression-free survival rate in the combined treatment group (18\% [95\% CI 13.1-22.5]) was much higher over the chemotherapy alone group (5\% [95\% CI 2.4-8.0]), suggesting additional follow-up time for patient events is necessary. It is interesting to notice that IMpower133 reported higher immune-related adverse events (irAEs; Table 1). One reason for this may be reflected in the trial design: while IMpower133 was a double-blinded study, CASPIAN was an open-label trial, which could affect how patients and/or clinicians attribute irAEs. 
Table 1 A summary of therapeutic efficacy and adverse events

\begin{tabular}{|c|c|c|}
\hline & \multicolumn{2}{|l|}{ A vs. B } \\
\hline & IMpower133 & CASPIAN \\
\hline \multicolumn{3}{|l|}{ Efficacy } \\
\hline PFS (in months) & 5.2 vs. 4.3 & 5.1 vs. 5.4 \\
\hline HR $(95 \% \mathrm{Cl})$ & $0.77(0.62-0.96)$ & $0.78(0.65-0.94)$ \\
\hline \multicolumn{3}{|l|}{ PFS\% } \\
\hline At 6 months & $30.9 \%$ vs. $22.4 \%$ & $45 \%$ vs. $46 \%$ \\
\hline At 12 months & $12.6 \%$ vs. $5.4 \%$ & $18 \%$ vs. $5 \%$ \\
\hline OS (in months) & 12.3 vs. 10.3 & 13.0 vs. 10.3 \\
\hline HR $(95 \% \mathrm{Cl})$ & $0.76(0.60-0.95)$ & $0.73(0.59-0.91)$ \\
\hline OS\% at 12 months & $51.7 \%$ vs. $38.2 \%$ & $54 \%$ vs. $40 \%$ \\
\hline \multicolumn{3}{|l|}{ trAEs } \\
\hline All grades & $94.9 \%$ vs. $92.3 \%$ & $89 \%$ vs. $90 \%$ \\
\hline Grades 3-4 & $56.6 \%$ vs. $56.1 \%$ & $46 \%$ vs. $52 \%$ \\
\hline SAES & $22.7 \%$ vs. $18.9 \%$ & $13 \%$ vs. $19 \%$ \\
\hline \multicolumn{3}{|l|}{ irAEs } \\
\hline All grades & $39.9 \%$ vs. $24.5 \%$ & $20 \%$ vs. $3 \%$ \\
\hline Grades 3-4 & $9.1 \%{ }^{*}$ vs. $2.6 \% *$ & $5 \%$ vs. $<1 \%$ \\
\hline
\end{tabular}

$A$ chemotherapy + immunotherapy, $B$ chemotherapy alone, $H R$ hazard ratio, $95 \%$ Cl 95\% confidence interval, trAEs treatment-related adverse events, AEs adverse events, SAEs severe adverse events, irAEs immune-related adverse events

*Calculated using Table S10 in the supplementary appendix provided by the authors

Despite the survival benefit observed in both studies, the absolute improvement in OS remains quite small, and not even statistically significant in the recent KEYNOTE-604 using anti-PD-1 agent pembrolizuamb in combination with platinum-etoposide (not yet published, from Merck's press release [4]). This is in sharp contrast to the significant OS benefit using anti-PD-1/L1 agents in NSCLC patients [5], suggesting the PD-1/L1 axis may not be the major $\mathrm{T}$ cell co-inhibitory pathway, which is consistent with low PD-L1 expression reported in SCLC [6, 7], and co-suppression of other immune checkpoints is likely needed to exert the maximal benefit from immunotherapy. In fact, two recent studies have demonstrated that PD-L1 can bind in cis (same cell) to CD80 [8, 9], which interact with both the co-inhibitory receptor CTLA-4 and co-stimulatory receptor CD28. By disrupting PD-L1:CD80 heterodimers, anti-PD-L1 could license high-avidity CD80:CTLA-4 interactions to unleash regulatory $\mathrm{T}$ cell-mediated depletion of $\mathrm{CD} 80$ from antigen-presenting cells, thereby inhibiting CD28 costimulation-this rationalizes the combination of anti-PDL1 with anti-CTLA-4 for a maximal anti-tumor effect [9]. In consistent with this, CASPIAN has a 4-drug arm including the anti-CTLA- 4 agent tremelimumab (in addition to durvalumab plus platinum-etoposide) that is currently ongoing. Comparison of this arm to the other two (platinum-etoposide with or without durvalumab) will be highly anticipated despite the earlier negative result from the
CA184-156 study [3]. Furthermore, co-targeting other coinhibitory receptors such as the $\mathrm{T}$ cell immunoreceptor with Ig and ITIM domains (TIGIT) is also of great interest (there is an ongoing study SKYSCRAPER-02, ClinicalTrials. gov Identifier: NCT04256421), especially considering its ligand CD155 (or poliovirus receptor (PVR)) is broadly expressed in both the SCLC cell lines and patient tumor tissue [10], and co-blockade of TIGIT and PD-1/L1 was found synergistic [11]. Finally, consolidative thoracic radiotherapy (CTRT) may further improve the survival benefit since $75 \%$ of patients with ES-SLCC could have persistent intrathoracic disease following induction chemotherapy [12], and CTRT has been shown to provide an OS benefit in patients who respond to initial chemotherapy [13]. It is hoped that radiation could enhance the immunogenicity of these tumors through promoting the release of tumor antigens [14], therefore enhance immunotherapy response. Importantly, a recent phase 1 trial of pembrolizumab in combination with thoracic radiation after induction chemotherapy for ES-SCLC demonstrated this combination was well tolerated [15].

In summary, these two studies provided strong evidence to support the use of immune checkpoint blockade in ESSCLC. However, questions remain regarding whether anti-PD-1/L1 in combination with other immune checkpoint inhibitors could further enhance the overall survival, and whether radiotherapy should be combined with chemoimmunotherapy in ES-SCLC.

\section{Abbreviations \\ APC: Antigen-presenting cell; CTRT: Consolidative thoracic radiotherapy; HR: Hazard ratio; NSCLC: Non-small cell lung cancer; OS: Overall survival; PCI: Prophylactic cranial irradiation; PD-1: Programmed cell death protein 1; PD-L1: Programmed death-ligand 1; PFS: Progression-free survival; \\ SCLC: Small cell lung cancer}

\section{Acknowledgements}

The authors would like to acknowledge Dr. Delong Liu for his critical reading and constructive comments.

\section{Authors' contributions}

JZ conceived the study. $\mathrm{CH}$ extracted the data and provided the initial draft. GNG and JZ provided critical revisions for this manuscript. All authors read and approved the final manuscript.

\section{Funding}

This work was supported by the Affiliated Hospital of Southwest Medical University Doctoral Research Initiation Fund $(\mathrm{CH})$, the University of Kansas Start-up Funds (JZ, GNG), the "Play with a Pro" Lung Cancer Research Fund of the University of Kansas Cancer Center (JZ), and NIH NIGMS COBRE Grant (P20GM130423) (GNG).

Availability of data and materials

Extracted from the literature.

Ethics approval and consent to participate

Not applicable to this letter.

Consent for publication

All authors read and approved the final manuscript for publication. 


\section{Competing interests}

The authors report no competing interests.

\section{Author details}

'Department of Respiratory and Critical Care Medicine II, The Affiliated Hospital of Southwest Medical University, 25 Taiping Street, Luzhou 646000 Sichuan, China. ${ }^{2}$ Division of Medical Oncology, Department of Internal Medicine, University of Kansas Cancer Center, University of Kansas Medical Center, 3005 Wahl Hall East, 3901 Rainbow Blvd, Kansas City, KS 66160, USA. ${ }^{3}$ Department of Radiation Oncology, University of Kansas Cancer Center, University of Kansas Medical Center, 3005 Wahl Hall East, 3901 Rainbow Blvd, Kansas City, KS 66160, USA. ${ }^{4}$ Department of Cancer Biology, University of Kansas Cancer Center, University of Kansas Medical Center, 3901 Rainbow Blvd, Kansas City, KS 66160, USA.

Received: 27 January 2020 Accepted: 27 March 2020

Published online: 05 June 2020

\section{References}

1. Paz-Ares L, Dvorkin M, Chen Y, Reinmuth N, Hotta K, Trukhin D, Statsenko G, Hochmair MJ, Ozguroglu M, Ji JH, Voitko O, Poltoratskiy A, Ponce S, Verderame F, Havel L, Bondarenko I, Kazarnowicz A, Losonczy G, Conev NV, Armstrong J, Byrne N, Shire N, Jiang H, Goldman JW, investigators C: Durvalumab plus platinum-etoposide versus platinum-etoposide in firstline treatment of extensive-stage small-cell lung cancer (CASPIAN): a randomised, controlled, open-label, phase 3 trial. Lancet 2019 . 394(10212):1929-1939.

2. Horn L, Mansfield AS, Szczesna A, Havel L, Krzakowski M, Hochmair MJ, Huemer F, Losonczy G, Johnson ML, Nishio M, Reck M, Mok T, Lam S, Shames DS, Liu J, Ding B, Lopez-Chavez A, Kabbinavar F, Lin W, Sandler A, Liu SV, Group IMS. First-line atezolizumab plus chemotherapy in extensive-stage small-cell lung cancer. N Engl J Med. 2018;379(23):2220-9.

3. Reck M, Luft A, Szczesna A, Havel L, Kim SW, Akerley W, Pietanza MC, Wu YL, Zielinski C, Thomas M, Felip E, Gold K, Horn L, Aerts J, Nakagawa K, Lorigan P, Pieters A, Kong Sanchez T, Fairchild J, Spigel D. Phase III randomized trial of ipilimumab plus etoposide and platinum versus placebo plus etoposide and platinum in extensive-stage small-cell lung cancer. J Clin Oncol. 2016;34(31):3740-8.

4. Merck: Merck's KEYTRUDA (pembrolizumab) in combination with chemotherapy significantly improved progression-free survival compared to chemotherapy alone as first-line treatment for extensive stage small cell lung cancer. 2020, https://investors.merck.com/news/ press-release-details/2020/Mercks-KEYTRUDA-pembrolizumab-inCombination-with-Chemotherapy-Significantly-Improved-ProgressionFree-Survival-Compared-to-Chemotherapy-Alone-as-First-Line-Treatmentfor-Extensive-Stage-Small-Cell-Lung-Cancer/defaultaspx.

5. Zhang C, Leighl NB, Wu YL, Zhong WZ. Emerging therapies for non-small cell lung cancer. J Hematol Oncol. 2019:12(1):45.

6. Yasuda Y, Ozasa H, Kim YH. PD-L1 expression in small cell lung cancer. J Thorac Oncol. 2018;13(3):e40-1.

7. Carvajal-Hausdorf D, Altan M, Velcheti V, Gettinger SN, Herbst RS, Rimm DL, Schalper KA. Expression and clinical significance of PD-L1, B7-H3, B7-H4 and TILs in human small cell lung cancer (SCLC). J Immunother Cancer. 2019;7(1):65.

8. Sugiura D, Maruhashi T, Okazaki IM, Shimizu K, Maeda TK, Takemoto T, Okazaki T. Restriction of PD-1 function by cis-PD-L1/CD80 interactions is required for optimal T cell responses. Science. 2019;364(6440):558-66.

9. Zhao Y, Lee CK, Lin CH, Gassen RB, Xu X, Huang Z, Xiao C, Bonorino C, Lu LF, Bui JD, Hui E. PD-L1:CD80 cis-heterodimer triggers the co-stimulatory receptor CD28 while repressing the inhibitory PD-1 and CTLA-4 pathways. Immunity. 2019;51(6):1059-73 e1059.

10. Yu H, Koczara C, Lohinai Z, Badzio A, Czapiewski P, Döme B, Moldvay J, Fillinger J, Gao D, Ellison K, Ren S Jr. CC, Rivard C, Hirsch F: Expression of the immune checkpoint axis-PVR/TIGIT in small cell lung cancer. Journal of Thoracic Oncology. 2018;13(10):S974-5.

11. Johnston RJ, Comps-Agrar L, Hackney J, Yu X, Huseni M, Yang Y, Park S, Javinal V, Chiu H, Irving B, Eaton DL, Grogan JL. The immunoreceptor TIGIT regulates antitumor and antiviral CD8(+) T cell effector function. Cancer Cell. 2014;26(6):923-37.

12. Slotman B, Faivre-Finn C, Kramer G, Rankin E, Snee M, Hatton M, Postmus P, Collette L, Musat E, Senan S, Group ERO, Lung Cancer G. Prophylactic cranial irradiation in extensive small-cell lung cancer. N Engl J Med. 2007; 357(7):664-72.

13. Slotman BJ, van Tinteren H, Praag JO, Knegjens JL, El Sharouni SY, Hatton M, Keijser A, Faivre-Finn C, Senan S. Use of thoracic radiotherapy for extensive stage small-cell lung cancer: a phase 3 randomised controlled trial. Lancet. 2015;385(9962):36-42.

14. Wilkins A, McDonald F, Harrington K, Melcher A. Radiotherapy enhances responses of lung cancer to CTLA-4 blockade. J Immunother Cancer. 2019;7(1):64.

15. Welsh JW, Heymach JV, Chen D, Verma V, Cushman TR, Hess KR, Shroff G, Tang C, Skoulidis F, Jeter M, Menon H, Nguyen QN, Chang JY, Altan M, Papadimitrakopoulou VA, Simon GR, Raju U, Byers L, Glisson B. Phase I trial of pembrolizumab and radiation therapy after induction chemotherapy for extensive-stage small cell lung cancer. J Thorac Oncol. 2020;15(2):266-73.

\section{Publisher's Note}

Springer Nature remains neutral with regard to jurisdictional claims in published maps and institutional affiliations.

Ready to submit your research? Choose BMC and benefit from

- fast, convenient online submission

- thorough peer review by experienced researchers in your field

- rapid publication on acceptance

- support for research data, including large and complex data types

- gold Open Access which fosters wider collaboration and increased citations

- maximum visibility for your research: over $100 \mathrm{M}$ website views per year

At BMC, research is always in progress.

Learn more biomedcentral.com/submissions 